\title{
Small bowel schwannoma revealed during an inguinal hernia: a case report
}

\author{
Aziz Zentar ${ }^{1}$, Youssef Tijani ${ }^{2 *}$, Hakim Elkaoui ${ }^{1}$, Jihad Elghanmi ${ }^{3}$, Khalid Sair ${ }^{1}$, Mustafa Taberkant ${ }^{2}$ \\ and Hassan Taoufik Chtata ${ }^{2}$
}

\begin{abstract}
Introduction: The association of bowel tumor and inguinal hernia is rare. We report according to our research the first case of the migration of a small bowel schwannoma into an inguinal hernia.

Case presentation: We report the case of a 51-year-old Moroccan malen admitted for a non-reducible right inguinal hernia in which surgical exploration showed the presence of a small bowel tumor that had migrated into his hernia sac. A histopathological examination of the tumor was in favor of a small bowel schwannoma.
\end{abstract}

Conclusion: Small bowel schwannoma is an exceptional clinical entity for which the diagnosis is difficult; its confirmation needs histological and immunohistochemical studies.

Keywords: Inguinal hernia, Schwannoma, Small bowel

\section{Introduction}

The migration of an intestinal tumor into inguinal hernia is a very rare entity. However the migration of a schwannoma of the small bowel into inguinal hernia is exceptional.

We report according to our research the first case of migration of small bowel schwannoma into an inguinal hernia.

\section{Case presentation}

We report the case of a 51-year-old Moroccan man with no past medical history who presented with a right inguinal mass looking like an inguinal hernia.

The clinical history started 1 year ago with the appearance of a right inguinal mass, impulsive during cough and reducible.

He observed an increase in the mass volume, and the appearance of a second hard and non-reducible mass 3 months later.

A clinical examination showed the presence of two inguinal masses the former soft and reducible and the latter hard and non-reducible. There was no associated

\footnotetext{
* Correspondence: dr.yousseftijani@gmail.com

${ }^{2}$ Department of Vascular Surgery, Mohammed V Military Hospital,

Mohammed V University of Rabat, Street corner souss-qahira, Nuild 16, №6

Kenitra, Rabat, Morocco

Full list of author information is available at the end of the article
}

nausea or vomiting. He had a history of hypertension for the previous 9 years. He had no significant changes in standard biochemical findings. The first diagnosis was the migration of his bowel in the hernia sac.

During surgical exploration we found an indirect inguinal hernia; however, at the opening of the sac we discovered a $10 \mathrm{~cm}$ mass originating from the ileal portion of his bowel tract (Figure 1).

We could not find any other mass in the examination of the remaining parts of his digestive system.

Our surgery consisted of the resection of a reddish well-encapsulated tumor, measuring $10 \mathrm{~cm}$ in diameter, originating from the antimesenteric border of the small bowel, without obstruction of its lumen leaving a $6 \mathrm{~cm}$ (Figures 2 and 3) safety margin from both sides of the termino-terminal anastomosis.

Hernia treatment was done according to the Lichtenstein procedure.

An anatomopathological study showed the presence of fusiform cells, in which the immunochemical study demonstrated cells expression of antibodies peroxidase and the immunostaining of cells was in favor of antiPS100, and the non-expression of anti-cluster of differentiation (CD) 117 and anti-desmin, hence proving its neurological nature schwannoma (Figure 4). 


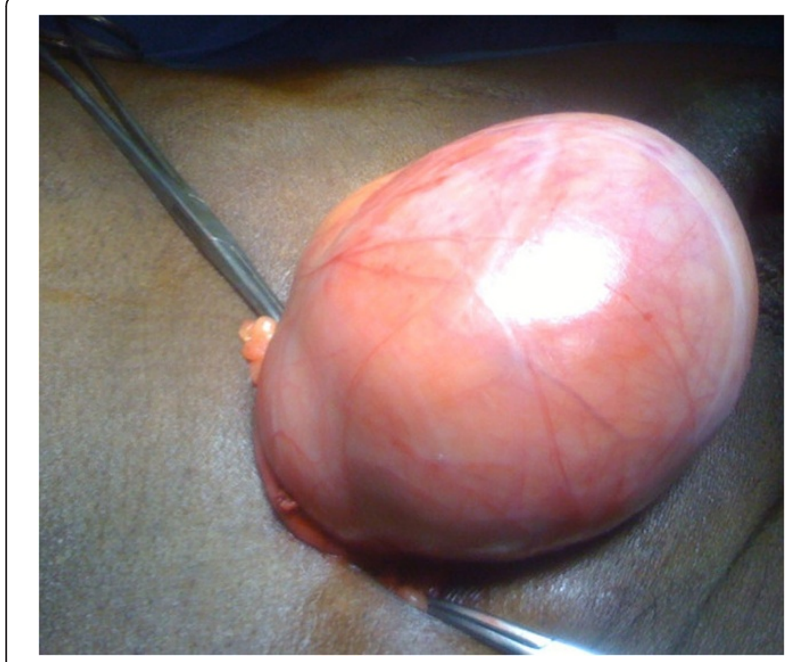

Figure 1 Operative view showing a $10 \mathrm{~cm}$ mass located on the bowel.

\section{Discussion}

The content of $10 \%$ of inguinal hernias is the bowel system [1]. The literature reveals that hernias may also contain different abdominal organs, such as urological and gynecological organs [2,3]; however less than $0.5 \%$ of hernias contain a tumor [4]. According to Lejar's classification of primary tumors in the hernia sac, we may differentiate two types: saccular and intrasaccular [5]. Saccular tumors involve the hernia sac such as mesothelioma; intrasaccular tumors involve organs inside the sac. The majority of intrasaccular tumors are of intestinal origin.

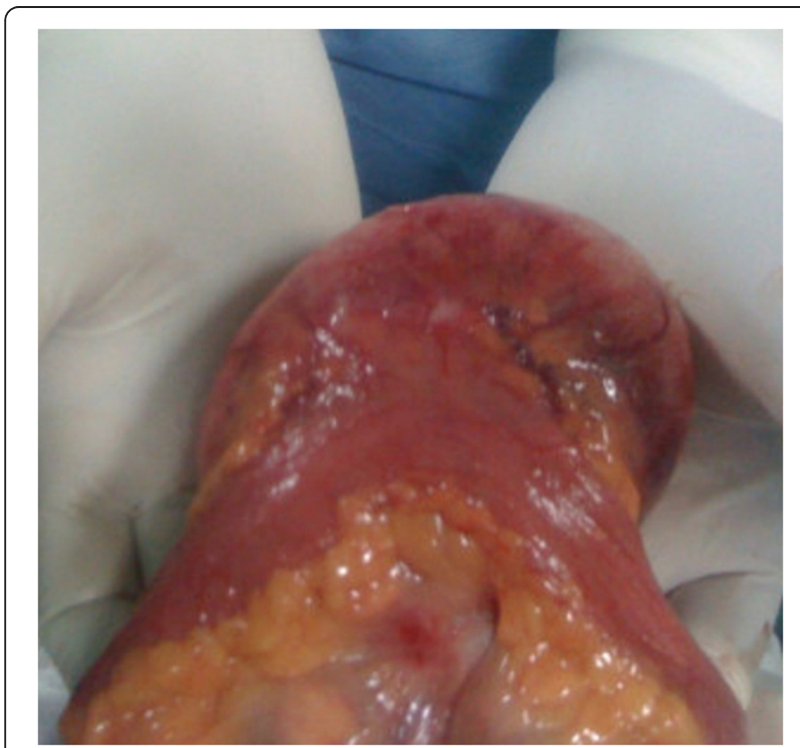

Figure 2 Operative view showing the mass is attached to the antimesenteric edge.

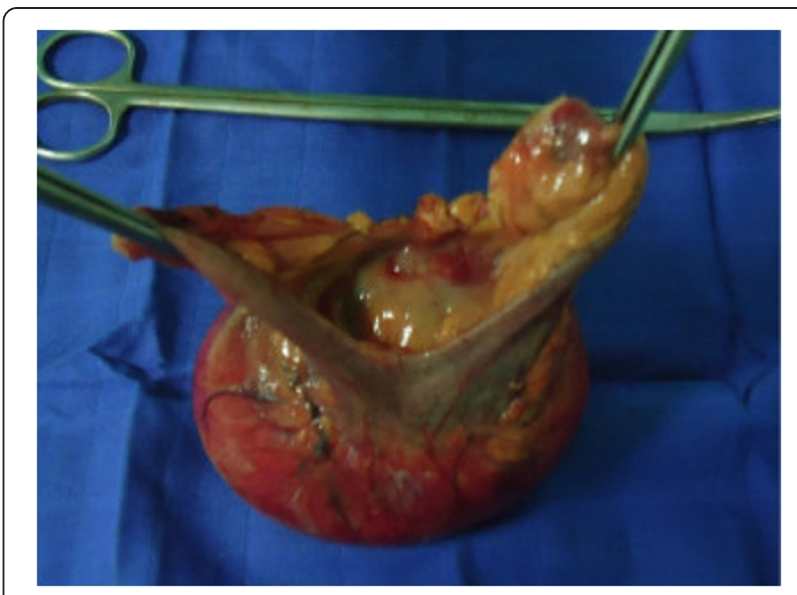

Figure 3 View showing the mass after resection.

In a series of 22,000 inguinal hernioplasties described by Nicholson et al. [6], they found that the incidence of tumor metastasis into the inguinal region is $0.07 \%$ of which $40 \%$ of the tumor metastases are secondary to intestinal tumor. The coexistence of an intra-abdominal mass and inguinal hernia was also reported [6-10], one possible explanation for this is the increased intraabdominal pressure secondary to the presence of an intra-abdominal tumor, particularly in older patients $[9,11]$. In our case report, the histopathological study was in favor of bowel schwannoma. Schwannoma localization in the bowel tract is rare and not frequently described in the literature, and it belongs to tumors of the bowel system which include digestive stromal tumors and differentiated tumors, which are less frequent [12]; the preferential localization of digestive tube schwannoma is the stomach $[13,14]$. Other localizations are described but are rare: colon, rectum and esophagus [15-17]. The clinical presentation of this tumor is not specific, frequently the patient complains of dyspepsia and epigastric pain

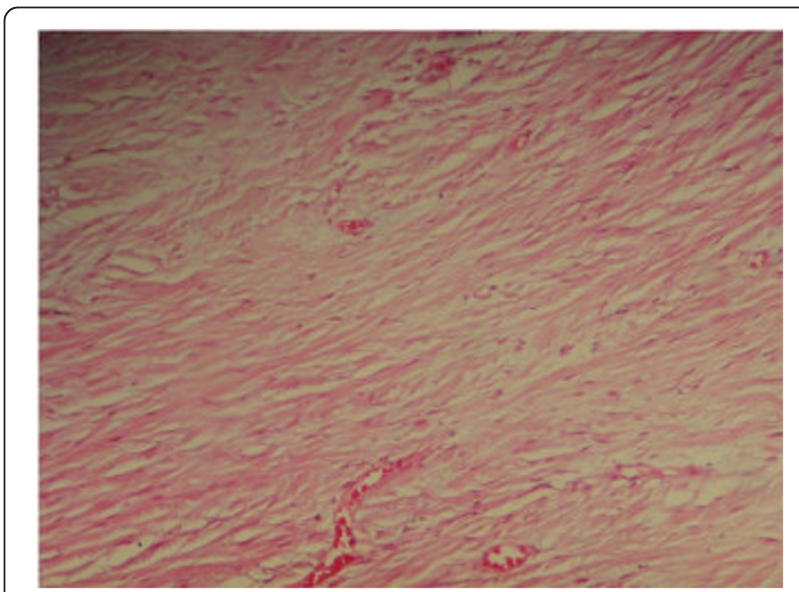

Figure 4 Anatomopathologic aspect of bowel schwannoma. 
$[13,14,18]$. In lower localization, the patient may complain of severe constipation and rectorrhagia [15]. The age of the patient varies from 18- to 87-years old, with a mean age of 65 years [15]; a slight predominance in women is found. Tumor [13-16] size varies from 0.5 to $11 \mathrm{~cm}$ [18] and giant schwannoma remain exceptional [17]. Malignant schwannoma localization in the digestive tract is not described [19].

In general, at endoscopic examination, the tumor appears submucosal with a large protrusion into the lumen of the digestive tube associated to small erosions of the mucosa. A biopsy is usually negative [20] and the diagnosis is based on the anatomopathological study of the removed tumor. In immunostaining studies schwannomas are always positive for proteins S100, positive for glial fibrillary acidic protein and CD57 marker but less constant and always negative for muscle markers [14]. The treatment of colorectal schwannoma is segmental colectomy, hemicolectomy or enucleation [15]. In fact, we could not find the association between Von Recklinghausen disease and the patient having digestive schwannoma [13-15,21].

We should differentiate between schwannomas and digestive stromal tumors. The latter are rare; they frequently originate from the connective system of the digestive tube [21].

Four types are identified [13]:

- Smooth muscle cells tumor.

- Nervous system tumor.

- Nervous and smooth muscle cells tumors.

- Undifferentiated tumor.

Stomach and small bowel are the most frequent localization.

All submucosal tumors of the digestive layer are considered stromal tumors; neither endoscopy nor echoendoscopy may confirm the diagnosis, only histological examination and immunohistochemical study may give us the precise diagnosis. Digestive stromal tumors show structural and immunophenotypic heterogeneity according to the segment in the digestive tube, and in the same tumor, the expression of CD117 is frequent but less constant [11].

\section{Conclusions}

The association of inguinal hernia and bowel schwannoma is exceptional; the prognosis is favorable.

The main difficulty is in precise diagnosis and for this histological and immunohistochemical studies are necessary.

\section{Consent}

Written informed consent was obtained from the patient for publication of this case report and any accompanying images. A copy of the written consent is available for review by the Editor-in-Chief of this journal.

\section{Abbreviations}

ANTI PS 100: Antibodies peroxidase immunostaining 100; CD: Cluster of differentiation.

\section{Competing interests}

The authors declare that they have no competing interests.

\section{Authors' contributions}

AZ reviewed our patient's case, data and figures, and was a major contributor in writing the manuscript. $\mathrm{HC}$ and $\mathrm{YT}$ reviewed our patient's case and data, completed subsequent drafts of the manuscript and were major contributors in writing the manuscript. HE and JE were involved during the initial presentation of our patient's case and were major contributors in writing the manuscript. KS was involved during the initial presentation of our patient's case. MT reviewed our patient's case, data, coordinated the authors and was a major contributor in writing the manuscript. All authors read and approved the final manuscript.

\section{Acknowledgement}

This manuscript was prepared during the corresponding author's training and was supported by the authors.

\section{Author details}

${ }^{1}$ Department of Digestive Surgery, Mohammed V Military Hospital, Mohammed V University of Rabat, Rabat, Morocco. ${ }^{2}$ Department of Vascular Surgery, Mohammed V Military Hospital, Mohammed V University of Rabat, Street corner souss-qahira, Nuild 16, №6 Kenitra, Rabat, Morocco.

${ }^{3}$ Department of Urology B, Avicenne University Hospital, Rabat, Morocco.

Received: 6 March 2014 Accepted: 21 July 2014

Published: 26 August 2014

\section{References}

1. McFayden BV, Mathis CR: Inguinal herniorrhaphy: complications and recurrences. Semin Laparosc Surg 1994, 1:128-140.

2. Habib FA, McAleese P, Kolachalam RB: Laparoscopic approach to the management of incarcerated hernia of appendices epiploicae: report of two cases and review of the literature. Surg Laparosc Endosc 1998, 8:425-428

3. Oruc MT, Akbulut Z, Ozozan O, Coskun F: Urological findings in inguinal hernias: a case report and review of the literature. Hernia 2004, 8:76-79.

4. Yoell JH: Surprises in inguinal hernial sacs, diagnosis of tumors by microscopic examination. Calif Med 1959, 91:146-148.

5. Lejar J: Neoplasmesherniairesetperi-herniaires. Gaz Hosp 1889, 62:801.

6. Nicholson CP, Donohue JH, Thompson GB, Lewis JE: A study of metastatic cancer found during inguinal hernia repair. Cancer 1992, 69:3008-3011.

7. Hale MDA, Solla MJA: Complete colonic obstruction caused by a sigmoid colon cancer incarcerated in an inguinal hernia sac. South Med J 1991, 84:1280-1281

8. Lowenfels AB, Ahmed N, Rohman M, Lefkowitz M: Hernia-sac cancer. Lancet 1969, 1:651.

9. Terezis NL, Dawis WC, Jackson FC. Carcinoma of colon associated with inguinal hernia. New Eng J Med 1963, 268:774-776.

10. Wlodarczyk A, Bielecki K, Ciesielski A, Kozicki I: Coexistence of left inguinal hernia and left colon cancer - a case report and literature review. Mater Med Pol 1996, 28:33-34.

11. Geelhoed GW, Millar RC, Ketcham AS: Hernia presentation of cancer in the groin. Surgery 1974, 75:436-441

12. Bedossa P, Martin E: Quoi de neufsur les tumeursconjonctives du tube digestif? Ann Pathol 1994, 14:350-356.

13. Prevot S, Bienvenu L, Vaillant JC, Saint-Maur PP: Benign schwannoma of the digestive tract: a clinicopathologic and immunohistochemical study of five cases, including a case of esophageal tumor. Am J Surg Pathol 1999, 23:431-436.

14. Sarlomo-Rikala M, Miettinen M: Gastric schwannoma: a clinicopathological analysis of six cases. Histopathology 1995, 27:355-360. 
15. Miettinen M, Shekitka KM, Sobin LH: Schwannomas in the colon and rectum: a clinicopathologic and immunohistochemical study of 20 cases. Am J Surg Pathol 2001, 25:846-855.

16. Daimaru Y, Kido H, Hashimoto H, Enjoji M: Benign schwannoma of the gastrointestinal tract: a clinicopathologic and immunohistochemical study. Hum Pathol 1988, 19:257-264.

17. Nabeya Y, Watanabe Y, Tohnosu N, Yamazaki M, Matsuda M, Akutsu N: Diffuse schwannoma involving the entire large bowel with huge extramural development: report of a case. Surg Today 1999, 29:637-641.

18. Iwamoto CA, Garcia CF, Razzak M: Pathologic quiz case: A 23-year-old woman with a polypoid gastric mass. Arch Pathol Lab Med 2003, 127:e43-e44.

19. Miettinen M, Lasota J: Gastrointestinal stromal tumors - definition, clinical, histological, immunohistochemical, and molecular genetic features and differential diagnosis. Virchows Arch 2001, 438:1-12.

20. Jacobson BC, Hirsch MS, Lee JH, Van Dam J, Shoji B, Farraye FA: Multiple asymptomatic plexiformschwannomas of the sigmoid colon: a case report and review. Gastrointest Endosc 2001, 53:801-804.

21. Balaton AJ, Coindre JM, Cvitkovic F: Tumeursstromales digestives. Gastroenterol Clin Biol 2001, 25:473-482.

doi:10.1186/1752-1947-8-287

Cite this article as: Zentar et al: Small bowel schwannoma revealed during an inguinal hernia: a case report. Journal of Medical Case Reports 2014 8:287.

\section{Submit your next manuscript to BioMed Central and take full advantage of:}

- Convenient online submission

- Thorough peer review

- No space constraints or color figure charges

- Immediate publication on acceptance

- Inclusion in PubMed, CAS, Scopus and Google Scholar

- Research which is freely available for redistribution 